\title{
INFLUENCING FACTORS OF STROKE AWARENESS AMONG HYPERTENSIVE PATIENTS IN COMMUNITY HEALTH CENTERS IN INDONESIA
}

\section{Author Information}

Ismail Setyopranoto ${ }^{1}$, Arif Setyo Upoyo $^{2}$, Atyanti Isworo ${ }^{2}$, Yunita Sari ${ }^{2}$, Amelia Nur Vidyanti $^{1 *}$

${ }^{1}$ Department of Neurology, Faculty of Medicine, Public Health, and Nursing, Universitas Gadjah Mada, Yogyakarta 55281, Indonesia

${ }^{2}$ Department of Nursing, Faculty of Health Sciences, Universitas Jenderal Soedirman, Purwokerto, Central Java 53122, Indonesia

*Correspondence:

Amelia Nur Vidyanti

Tel.: +62-274-543473

Email: amelia.nur.v@ugm.ac.id

\section{Abstract}

The global burden of stroke is still high, particularly in developing countries, with hypertension serves as the main risk factor. Knowledge related to stroke is essential to establish better prevention strategies. This study aimed to identify factors associated with stroke awareness among hypertensive patients in Indonesia. This was a cross-sectional study conducted in five Community Health Centers in Indonesia. We used a standardized questionnaire to asses stroke awareness and the influencing factors. The knowledge on hypertension was assessed using Hypertension Knowledge Level Scale (HK-LS). Multivariate logistic regression analysis was performed to measure factors associated with stroke awareness. A total of 457 hypertensive patients were included. Majority of patients $(77.46 \%)$ had low stroke awareness. Having higher 
knowledge on hypertension, higher income, and a history of previous stroke were associated with higher level of stroke awareness (odds ratio [OR] 1.878, 95\%CI 1.176-2.999, p 0.008; OR 1.887, 95\%CI 1.170-3.045, p 0.009; OR 5.276, 95\%CI 2.210-12.594, p<0.001, respectively). This study suggests that knowledge on hypertension, income, and history of previous stroke are factors which may influence the level of stroke awareness. This emphasizes the need to provide better campaign and education program to raise stroke awareness in a community setting.

Keywords: stroke awareness, hypertensive patients, community health center, Indonesia

\section{Background}

Stroke is the leading cause of morbidity and disability worldwide [1]. The global burden of stroke is still high with the estimated incidence is 15 million new cases per year, in which two thirds of them occur in developing countries [2]. The disability-adjusted life years of stroke patients was more than $87 \%$ in developing countries and this was seven times higher than in developed countries [3,4].

Indonesia has the highest rates of age-sex standardized mortality and disability adjusted life-years among South East Asian (193.3/100,000 person-years and 3,382.2/100,000 people, respectively) [5]. The average age of stroke patients in Indonesia is lower than those in developed countries [6], thus leads to higher disability rate, reduce the quality of life and more economic lost [7]. The high burden of stroke is attributable to modifiable risk factors such as behavioral, metabolic, and environmental risk factors [8]. Hence, knowledge related to stroke warning signs and risk factors is crucial to reduce the incidence of stroke and prevent subsequent mortality [9]. 
A recent cross-sectional study in Spain revealed that the knowledge related to the warning signs and risk factors among hospitalized stroke patients was low. Previous history of stroke and high education level were predictors which could increase the knowledge [10]. In contrast, prior study in Nigeria demonstrated different findings that the knowledge of stroke risk factors was quite high among hypertensive and diabetic patients. However, the compliance with action to do stroke prevention was sub-optimal [11].

Hypertension is the most common risk factors for stroke and the main modifiable factor attributed to disability after stroke [12,13]. The Indonesia Family Life Survey-5 (IFLS-5) reported that the prevalence of hypertension in people with the mean age of 43.3 years old was quite high, reaching $33.4 \%$. In addition, the awareness of hypertension was low, the treatment and control were very poor [14]. These may further contribute to increase risk of stroke.

Raising public stroke awareness would be beneficial for better stroke prevention strategies, particularly for population at risk. Approximately $80 \%$ of new stroke incidence could be avoided by improving knowledge related to risk factors of stroke [15]. The knowledge about stroke as a complication of hypertension is also essential for establishing the effective prevention programs. Nevertheless, no prior studies reporting the level of stroke awareness in Indonesia. The present study aimed to identify the influencing factors of stroke awareness among hypertensive patients in Community Health Centers in Indonesia.

\section{Materials and Methods}

\section{Study Design and Participants}

This study had cross-sectional design. We included patients from five Community Health Centers in Banyumas Regency, Central Java Province, Indonesia during April - August 2019. These five Community Health Centers were located in rural (3) and urban (2) region, thus representing the characteristics of both populations. 
Hypertensive patients aged $>35$ years old who came to the Community Health Centers for a routine checkup were consecutively recruited. Hypertensive patients with comorbidities such as aphasia, dementia or other neuropsychiatric diseases were excluded from the study.

A total of 457 patients were investigated in this study. All patients signed a written informed consent prior to the investigation. Ethical approval for this study has been obtained from The Medical and Health Research Ethics Committee of Dr. Moewardi General Hospital with approval number: 789/VI/HREC/2019.

\section{Data Collection and Measurements}

We conducted a cross-sectional survey by interviewing the participants based upon a questionnaire. The questionnaire consists of four components, including demographic characteristics, knowledge on hypertension, comorbidities, and level of stroke awareness. The questionnaire was filled in by the investigators.

Demographic characteristics included sex, age, education level, marriage status (married/widow), living with (family/alone), and income. Income was categorized as $<$ minimum regional payment (MRP) or $<134 \mathrm{USD} /$ month, and $\geq \mathrm{MRP}(\geq 134 \mathrm{USD} / \mathrm{month})$ based on the minimum standard income in Indonesia [16].

We measured patients' knowledge on hypertension as a risk factor for stroke by using The Hypertension Knowledge-Level Scale (HK-LS). HK-LS has high validity and reliability for measuring the level of knowledge on hypertension in adults [17]. It has been translated and validated to Indonesian version with good reliability [18]. The final scale has 22 items related to hypertension which divided into six subdimensions namely definition, medical treatment, drug compliance, lifestyle, diet, and complications. The maximum score is 22 for the entire scale. The minimum score is zero for the entire scale and for all subdimensions [17]. HK-LS was further classified as low knowledge on hypertension (HK-LS $\leq 17)$ and high knowledge (HK-LS 18-22) [19]. 
Comorbidities included history of headache, medication adherence, history of hypertension (controlled/uncontrolled), history of diabetes mellitus, history of dyslipidemia, history of stroke, history of atrial fibrillation, history of heart failure, history of anxiety, and history of sleep apnea. Medication adherence was measured by five-item scale about selfreported adherence related to blood pressure medicine [20]. Patients were categorized as not adhere to the medication if the scale was $<5$, and adhere if the scale was 5 .

In the last part of the questionnaire, we asked participants regarding their perceived health status related to stroke risk. We measured their perception using Likert scale (1-5). Scale 1 means patient was very unsure to be at risk for a stroke, scale 2 means unsure, scale 3 means patient undecided, scale 4 means sure, and scale 5 means very sure. Patients with Likert scale $\leq 3$ were categorized as having low-level of stroke awareness, and those with Likert scale $>3$ were having high-level of stroke awareness.

\section{Statistical Analysis}

We performed the Chi square test to analyze the differences between categorical variables in the baseline characteristics. Factors associated with stroke awareness were measured using univariate logistic regression analysis. Subsequently, these associated factors were further analyzed using multivariate logistic regression to measure their contribution to stroke awareness after controlling the covariates. Statistical significance was indicated by a $p$ value of $<0.05$. SPSS version 16 was used for all the analyses.

\section{Results}

\section{Baseline characteristics}

Table 1 shows baseline characteristics of participants based on the level of stroke awareness. From total 457 patients, 354 (77.46\%) had low stroke awareness and 103 (22.54\%) with high stroke awareness. Most of the participants were female (80.74\%), aged more than 55 
years $(75.71 \%)$, had low education level (79.65\%), had low level of knowledge on hypertension $(56.02 \%)$ and had uncontrolled hypertension $(85.33 \%)$. Between participants with low and high stroke awareness, there were some notably differences including knowledge on hypertension (HK-LS), income level, history of hypertension, history of diabetes mellitus, and history of stroke.

Table 1. Baseline characteristics of participants based on the level of stroke awareness.

\begin{tabular}{|c|c|c|c|}
\hline \multirow{2}{*}{ Characteristics } & \multicolumn{2}{|c|}{ Stroke Awareness } & \multirow{2}{*}{$p$} \\
\hline & Low $(\mathrm{n}, \%)$ & $\operatorname{High}(\mathrm{n}, \%)$ & \\
\hline \multicolumn{4}{|l|}{ Sex } \\
\hline Male & $66(18.6)$ & $22(21.4)$ & 0.539 \\
\hline Female & $288(81.4)$ & $81(78.6)$ & \\
\hline \multicolumn{4}{|l|}{ Age (Years) } \\
\hline$<55$ & $84(23.7)$ & $27(26.2)$ & 0.605 \\
\hline$\geq 55$ & $270(76.3)$ & $76(73.8)$ & \\
\hline \multicolumn{4}{|l|}{ Education level } \\
\hline Low & 283 (79.9) & $81(78.6)$ & 0.773 \\
\hline High & $71(20.1)$ & $22(21.4)$ & \\
\hline \multicolumn{4}{|l|}{ Marriage Status } \\
\hline Married & 258 (72.9) & $70(68.0)$ & 0.329 \\
\hline Widow & $96(27.1)$ & $33(32.0)$ & \\
\hline \multicolumn{4}{|l|}{ Living with } \\
\hline Family & $185(52.3)$ & $48(46.6)$ & 0.312 \\
\hline Alone & 169 (47.7) & $55(53.4)$ & \\
\hline
\end{tabular}




\begin{tabular}{|c|c|c|}
\hline$<\mathrm{MRP}$ & $252(71.2)$ & $55(53.4)$ \\
\hline$\geq \mathrm{MRP}$ & $102(28.8)$ & 48 (46.6) \\
\hline
\end{tabular}

HK-LS

\begin{tabular}{|c|c|c|}
\hline Low & $211(59.6)$ & $45(43.7)$ \\
\hline High & $143(40.4)$ & $58(56.3)$ \\
\hline
\end{tabular}

History of headache

\begin{tabular}{|c|c|c|}
\hline No & $73(20.6)$ & $19(18.4)$ \\
\hline Yes & $281(79.4)$ & $84(81.6)$ \\
\hline
\end{tabular}

Medication Adherence

\begin{tabular}{|c|c|c|}
\hline No & $145(41.0)$ & $42(40.8)$ \\
\hline Yes & $209(59.0)$ & $61(59.2)$ \\
\hline
\end{tabular}

History of hypertension

Controlled

Uncontrolled

History of Diabetes Mellitus

\begin{tabular}{|c|c|c|}
\hline No & $214(60.5)$ & $45(43.7)$ \\
\hline Yes & $140(39.5)$ & $58(56.3)$ \\
\hline
\end{tabular}

History of hyperlipidemia

No

Yes

History of stroke

\begin{tabular}{|c|c|c|}
\hline No & 343 (96.9) & $90(87.4)$ \\
\hline Yes & $11(3.1)$ & $13(12.6)$ \\
\hline
\end{tabular}

History of atrial fibrillation

No

$314(88.7) \quad 91(88.3) \quad 0.921$ 
Yes

History of heart failure

No

Yes

History of anxiety

No

Yes

History of sleep Apnea

$40(11.3)$

$12(11.7)$

$$
\text { No }
$$

Yes

$$
336(94.9) \quad 94(91.3) \quad 0.166
$$

$$
18(5.1) \quad 9(8.7)
$$

$350(98.9) \quad 102(99.0) \quad 0.891$

$4(1.1) \quad 1(1.0)$

$346(97.7) \quad 101(98.1) \quad 0.846$

$8(2.3) \quad 2(1.9)$

HK-LS, Hypertension Knowledge Level Scale; MRP, minimum regional payment. $* p<0.05 ; * * p<0.001$

Table 2 presents the univariate analysis of factors associated with high stroke awareness. Participants with high knowledge of hypertension were $90 \%$ more likely to have high stroke awareness compared with their low knowledge counterpart (Odds ratio [OR] 1.902, 95\%CI: 1.221-2.963, p 0.004). Moreover, those with income $\geq$ MRP, history diabetes mellitus and history of stroke were more likely to have high stroke awareness than the counterpart (OR 2.156, 95\%CI: 1.374-3.383, p 0.001; OR 1.97, 95\%CI: 1.264-3.071, p 0.003; OR 4.504, 95\%CI: $1.953-10.390, \mathrm{p}<0.001$, respectively). Meanwhile, participants with history of uncontrolled hypertension were $46 \%$ less likely to have high stroke awareness (OR 0.536, 95\%CI: 0.305-0.944, p 0.029).

Table 2. Univariate analysis of factors associated with high stroke awareness

$\begin{array}{llll}\text { Characteristics } & \text { OR } & 95 \% \mathrm{CI} & p \text { value }\end{array}$




\section{Sex}

Male

Ref

Female

0.844

0.491-1.451

0.539

Age (Years)

$<55$

Ref

$\geq 55$

0.876

0.530-1.448

0.605

Education level

Low

High

HK-Ls

Low

High

Married Status

Married

Widow

Living with

Family

Alone/couple

Income

$<\mathrm{MRP}$

$\geq \mathrm{MRP}$
Ref

$1.083 \quad 0.632-1.854$

0.773

Ref

1.902

$1.221-2.963$

$0.004 *$

Ref

1.267

0.787-2.039

0.329

Ref

1.254

0.808-1.974

0.312

Ref

$2.156 \quad 1.374-3.383 \quad 0.001^{*}$ 
History of headache

$\begin{array}{llll}\text { No } & \text { Ref } & & \\ \text { Yes } & 1.149 & 0.658-2.000 & 0.628\end{array}$

Medication adherence
No
Ref
Yes
1.008
$0.653-1.590$
0.973

History of hypertension

Controlled

Ref

Uncontrolled

$\begin{array}{lll}0.536 & 0.305-0.944 & 0.029 *\end{array}$

History of diabetes mellitus

$\begin{array}{llll}\text { No } & \text { Ref } & & \\ \text { Yes } & 1.97 & 1.264-3.071 & 0.003^{*}\end{array}$

History of hyperlipidemia
No
Ref
Yes
$\begin{array}{lll}0.930 & 0.546-1.585 & 0.790\end{array}$

History of stroke

$\begin{array}{llll}\text { No } & \text { Ref } & & \\ \text { Yes } & 4.504 & 1.953-10.390 & <0.001 *\end{array}$

History of atrial fibrillation
No
Ref
Yes
1.035
$0.521-2.056$
0.921

History of heart failure
No
Ref
Yes
1.787
$0.778-4.108$
0.166

History of anxiety 


$\begin{array}{lccc}\text { No } & \text { Ref } & & \\ \text { Yes } & 0.858 & 0.095-7.760 & 0.891\end{array}$

History of sleep apnea

$\begin{array}{lccc}\text { No } & \text { Ref } & & \\ \text { Yes } & 0.856 & 0.179-4.097 & 0.846\end{array}$

HK-LS, $\overline{\text { Hypertension Knowledge Level Scale; MRP, minimum regional payment. }}{ }^{*} p<0.05$; $*^{* *} p<0.001$

Table 3 presents the multiple logistic regression of factors associated with stroke awareness after adjustment by controlling multiple covariates. We found that knowledge on hypertension, income, and history of stroke were independently associated with stroke awareness among hypertensive patients. Participants with higher knowledge on hypertension, higher income, and history of stroke were more likely to have high-stroke awareness. History of stroke was the most dominant factor which influenced stroke awareness (OR 5.276, 95\%CI:2.210-12.594, $\mathrm{p}<0,001)$.

Table 3. Multiple logistic regression of factors associated with stroke awareness after adjustment with covariates.

\begin{tabular}{lccc}
\hline \multicolumn{1}{c}{ Variable } & OR & $95 \%$ CI & $p$ \\
\hline HK-LS (high vs low) & 1.878 & $1.176-2.999$ & $0.008^{*}$ \\
Income ( $\geq$ MRP vs $<$ MRP) & 1.887 & $1.170-3.045$ & $0.009^{*}$ \\
History of hypertension (yes vs no) & 0.566 & $0.294-1.087$ & 0.087 \\
History of DM (yes vs no) & 1.564 & $0.932-2.624$ & 0.090
\end{tabular}


History of stroke (yes vs no) $\quad 5.276 \quad 2.210-12.594 \quad<0.001 * *$

$\overline{\text { HK-LS, Hypertension Knowledge Level Scale; MRP, minimum regional payment; DM, }}$ diabetes mellitus. ${ }^{*} p<0.05 ; * * p<0.001$

\section{Discussion}

The present study shows that patients who had high-level of knowledge on hypertension, higher income, and history of previous stroke were more likely to have high-level of stroke awareness. To our knowledge, this is the first study in Indonesia which demonstrated factors contribute to the level of stroke awareness among hypertensive patients.

In this study we found that the majority of the participants had low-level of stroke awareness. This finding is in accordance with prior studies which showed that most participants were not fully aware of stroke and its risk factors [15,21,22]. Moreover, the level of stroke awareness in the present study was positively associated with the level of knowledge on hypertension. Therefore, the reason why most of our patients had low stroke awareness was due to poor knowledge on hypertension. This may endanger their health status as patients could not prevent the future risk of stroke.

Corroborates with our findings, previous study reported that $78.3 \%$ patients had inadequate knowledge, $21.7 \%$ had moderate knowledge, and none of them had adequate knowledge on hypertension and stroke prevention [23]. Another cross-sectional study on hypertensive patients also demonstrated that $75.1 \%$ of participants had poor knowledge on stroke prevention [24]. Knowledge on hypertension is crucial to prevent increasing incidence of hypertension and to maintain normal blood pressure control [25]. Hence, knowledge deficits contributes to inadequate control of hypertension and poor medication adherence [19] which further increase the risk of stroke. Furthermore, two studies investigating the knowledge about 
stroke warning signs and risk factors in patients with acute cerebrovascular disease [26] and history of previous stroke [27] revealed similar findings.

In the present study, we also found that higher income was positively associated with stroke awareness. This finding is supported by prior study using data from the 2017 National Health Interview Survey in United States which showed that individuals with low income were more likely of not being aware of all stroke symptoms [28]. The level of monthly income is a factor that could predict stroke knowledge. Higher income is associated with good stroke knowledge [29]. Moreover, another cross-sectional study in Spain demonstrated that socioeconomic status including educational level, income, and employment status are independent factors for sufficient knowledge of stroke [30]. Patients with higher income are more likely to have better and prompt health-seeking behavior when they are being at risk of stroke [31].

Stroke awareness in this study is also influenced by having history of stroke. In accordance with our finding, a cross-sectional study among stroke patients in Spain reported that history of prior stroke was associated with higher knowledge on stroke warning signs and risk factors [10]. Another study showed that stroke survivors or patients with history of previous stroke were more likely to have more awareness on stroke warning signs including sudden numbness or weakness, sudden difficulty speaking or understanding speech, sudden dizziness, and sudden severe headache [32]. The contributing factor for higher stroke awareness among patients with history of prior stroke is the adequate information received during they stayed on hospital, from admission until discharge. This permits them to recognize the signs, symptoms, and risk factors of stroke which could prevent further delay in seeking care [10,27,33].

Results in the present study contribute to providing more evidence that stroke awareness is still insufficient in community setting. This indicates an urgent need to disseminate stroke education and awareness campaigns in Indonesia, particularly targeting people who have the 
higher risk of stroke. Nevertheless, this study has some limitations. First, stroke awareness in the present study was only related the participants' perceived health status of being at risk of stroke, using a "yes-no" questions. The investigation related to their knowledge on stroke warning signs was not explored. The cultural belief and perception regarding stroke and the risk factors for each participant were not either investigated. Second, duration of hypertension was not included in the analysis. In addition, we did not analyze whether the patients had endstage complications or not. Taken together, these may lead to bias and different findings. Third, the participants in this study were recruited only from five Community Health Centers in a region in Indonesia. Therefore, the findings need careful interpretation for generalization. Finally, we only used cross-sectional design. Thus, we could not provide the causal relationship between stroke awareness and the influencing factors although the direction of the association was consistent with prior studies.

\section{Conclusions}

Stroke awareness among hypertensive patients were still low. Knowledge on hypertension, income, and history of previous stroke are factors which may influence the level of stroke awareness among hypertensive patients. This emphasizes the need to provide better campaign and education program to raise stroke awareness in a community setting.

\section{Funding}

This study received no external funding.

\section{Acknowledgement}

The authors would like to thank the supporting staffs in five Community Health Centers in Banyumas (Puskesmas Purwokerto Timur, Purwokerto Utara, Kembaran, Sumbang, and 
Baturaden) for their technical supports. We are also grateful to the participants who provided their consent for participation in this study.

\section{Author Contributions}

Conceptualization, IS and ASU; methodology, IS, ASU, ANV; software, IS, ANV; validation, IS, AI, YS; formal analysis, ASU, ANV; investigation, IS, ASU; resources, IS and ASU; data curation, ASU; visualization, ANV; supervision AI and YS; writing-original draft preparation, IS; writing-review and editing, IS and ANV.

\section{Conflict of Interest}

The authors declare no conflict of interest.

\section{References:}

1. Mackay, J.; Mensah, G.; Mendis, S.; Greenlund, K. The Atlas of Heart Disease and Stroke. World Health Organization: Geneva, 2004.

2. $\quad$ Feigin, V.L.; Forouzanfar, M.H.; Krishnamurthi, R.; Mensah, G.A.; Connor, M.; Bennett, D.A.; Moran, A.E.; Sacco, R.L.; Anderson, L.; Truelsen, T. Global and regional burden of stroke during 1990-2010: findings from the Global Burden of Disease Study 2010. The Lancet 2014, 383, 245-255.

3. Johnston, S.C.; Mendis, S.; Mathers, C.D. Global variation in stroke burden and mortality: estimates from monitoring, surveillance, and modelling. The Lancet Neurology 2009, 8, 345354.

4. Gedefa, B.; Menna, T.; Berhe, T.; Abera, H. Assessment of risk factors and treatment outcome of stroke admissions at St. Paul's teaching hospital, addis ababa, Ethiopia. Journal of Neurology \& Neurophysiology 2017, 8, 1-6.

5. Venketasubramanian, N.; Yoon, B.W.; Pandian, J.; Navarro, J.C. Stroke epidemiology in south, east, and south-east Asia: a review. Journal of stroke 2017, 19, 286.

6. Setyopranoto, I.; Bayuangga, H.F.; Panggabean, A.S.; Alifaningdyah, S.; Lazuardi, L.; Dewi, F.S.T.; Malueka, R.G. Prevalence of Stroke and Associated Risk Factors in Sleman District of Yogyakarta Special Region, Indonesia. Stroke Research and Treatment 2019, 2019, 2642458, doi:10.1155/2019/2642458.

7. Donkor, E.S. Stroke in the 21st Century: A Snapshot of the Burden, Epidemiology, and Quality of Life. Stroke Research and Treatment 2018, 2018, 3238165, doi:10.1155/2018/3238165.

8. Feigin, V.L.; Roth, G.A.; Naghavi, M.; Parmar, P.; Krishnamurthi, R.; Chugh, S.; Mensah, G.A.; Norrving, B.; Shiue, I.; Ng, M. Global burden of stroke and risk factors in 188 countries, during 1990-2013: a systematic analysis for the Global Burden of Disease Study 2013. The Lancet Neurology 2016, 15, 913-924. 
9. Walker, R.W.; McLarty, D.G.; Kitange, H.M.; Whiting, D.; Masuki, G.; Mtasiwa, D.M.; Machibya, H.; Unwin, N.; Alberti, K.M. Stroke mortality in urban and rural Tanzania. The Lancet 2000, 355, 1684-1687.

10. Soto-Cámara, R.; González-Bernal, J.J.; González-Santos, J.; Aguilar-Parra, J.M.; Trigueros, R.; López-Liria, R. Knowledge on signs and risk factors in stroke patients. Journal of clinical medicine 2020, 9, 2557.

11. Arisegi, S.A.; Awosan, K.J.; Oche, M.O.; Sabir, A.A.; Ibrahim, M.T. Knowledge and practices related to stroke prevention among hypertensive and diabetic patients attending Specialist Hospital, Sokoto, Nigeria. Pan African Medical Journal 2018, 29, 1-17.

12. Mathers, C.; Stevens, G.; Mascarenhas, M. Global health risks: mortality and burden of disease attributable to selected major risks; World Health Organization: 2009.

13. Ezzati, M.; Lopez, A.D.; Rodgers, A.; Vander Hoorn, S.; Murray, C.J.; Group, C.R.A.C. Selected major risk factors and global and regional burden of disease. The Lancet 2002, 360, 13471360.

14. Peltzer, K.; Pengpid, S. The Prevalence and Social Determinants of Hypertension among Adults in Indonesia: A Cross-Sectional Population-Based National Survey. International Journal of Hypertension 2018, 2018, 5610725, doi:10.1155/2018/5610725.

15. Dar, N.Z.; Khan, S.A.; Ahmad, A.; Maqsood, S. Awareness of Stroke and Health-seeking Practices among Hypertensive Patients in a Tertiary Care Hospital: A Cross-sectional Survey. Cureus 2019, 11, e4774.

16. Badan Pusat Statistik (National Statistic Bureau Indonesia). Statistik Indonesia (Statistical Yearbook of Indonesia) 2019. BPS-Statistics Indonesia: Jakarta, 2019.

17. Baliz Erkoc, S.; Isikli, B.; Metintas, S.; Kalyoncu, C. Hypertension Knowledge-Level Scale (HKLS): a study on development, validity and reliability. International journal of environmental research and public health 2012, 9, 1018-1029.

18. Ernawati, I.; Fandinata, S.S.; Permatasari, S.N. Translation and Validation of the Indonesian Version of the Hypertension Knowledge-level Scale. Open Access Macedonian Journal of Medical Sciences 2020, 8, 630-637.

19. Jankowska-Polańska, B.; Uchmanowicz, I.; Dudek, K.; Mazur, G. Relationship between patients' knowledge and medication adherence among patients with hypertension. Patient preference and adherence 2016, 10, 2437.

20. Morisky, D.E.; Green, L.W.; Levine, D.M. Concurrent and predictive validity of a self-reported measure of medication adherence. Medical care 1986, 67-74.

21. Juraporn, P.; Ampai, A. Knowledge About Stroke and Awarness of Its Signals Among Hypertensive Patients Without Prior History of Stroke. Clinical Therapeutics 2015, 37, E28.

22. Abate, A.T.; Bayu, N.; Mariam, T.G. Hypertensive Patients' Knowledge of Risk Factors and Warning Signs of Stroke at Felege Hiwot Referral Hospital, Northwest Ethiopia: A CrossSectional Study. Neurology Research International 2019, 2019, 8570428, doi:10.1155/2019/8570428.

23. MA, S.M.; JOHN, J. Assess the prevalence of hypertension and knowledge regarding the prevention of stroke. Asian J Pharm Clin Res 2017, 10, 177-180.

24. Tibebu, N.S.; Emiru, T.D.; Tiruneh, C.M.; Nigat, A.B.; Abate, M.W.; Demelash, A.T. Knowledge on Prevention of Stroke and Its Associated Factors Among Hypertensive Patients at Debre Tabor General Hospital: An Institution-Based Cross-Sectional Study. Risk Management and Healthcare Policy 2021, 14, 1681.

25. Lugo-Mata, Á.; Urich-Landeta, A.; Andrades-Pérez, A.; León-Dugarte, M.; Marcano-Acevedo, L.; Guillen, M.J.L. Factors associated with the level of knowledge about hypertension in primary care patients. Medicina Universitaria 2017, 19, 184-188.

26. Sundseth, A.; Faiz, K.W.; Rønning, O.M.; Thommessen, B. Factors related to knowledge of stroke symptoms and risk factors in a Norwegian stroke population. Journal of Stroke and Cerebrovascular Diseases 2014, 23, 1849-1855. 
27. Zeng, Y.; He, G.P.; Yi, G.H.; Huang, Y.J.; Zhang, Q.H.; He, L.L. Knowledge of stroke warning signs and risk factors among patients with previous stroke or TIA in China. Journal of clinical nursing 2012, 21, 2886-2895.

28. Mszar, R.; Mahajan, S.; Valero-Elizondo, J.; Yahya, T.; Sharma, R.; Grandhi, G.R.; Khera, R.; Virani, S.S.; Lichtman, J.; Khan, S.U. Association between sociodemographic determinants and disparities in stroke symptom awareness among US young adults. Stroke 2020, 51, 35523561.

29. Kamran, S.; Bener, A.; Deleu, D.; Khoja, W.; Jumma, M.; Al Shubali, A.; Inshashi, J.; Sharouqi, I.; Al Khabouri, J. The level of awareness of stroke risk factors and symptoms in the Gulf Cooperation Council countries: Gulf Cooperation Council stroke awareness study. Neuroepidemiology 2007, 29, 235-242.

30. Ramirez-Moreno, J.; Alonso-Gonzalez, R.; Pacheco, D.P.; Millán-Nuñez, M.; Roa-Montero, A.; Constantino-Silva, A.; Aguirre-Sánchez, J. Effect of socioeconomic level on knowledge of stroke in the general population: a social inequality gradient. Neurología (English Edition) 2016, 31, 24-32.

31. Howard, V.J.; Lackland, D.T.; Lichtman, J.H.; McClure, L.A.; Howard, G.; Wagner, L.; Pulley, L.; Gomez, C.R. Care seeking after stroke symptoms. Annals of Neurology: Official Journal of the American Neurological Association and the Child Neurology Society 2008, 63, 466-472.

32. Lee, Y.-H. Comparison of Awareness of Stroke Warning Signs between Community-Dwelling Stroke Survivors and Families and the General Population without Stroke. Journal of stroke 2020, 22, 150.

33. Kim, Y.S.; Park, S.-S.; Bae, H.-J.; Cho, A.-H.; Cho, Y.-J.; Han, M.-K.; Heo, J.H.; Kang, K.; Kim, D.E.; Kim, H.Y. Stroke awareness decreases prehospital delay after acute ischemic stroke in Korea. BMC neurology 2011, 11, 1-8. 